\title{
ОСОБЕННОСТИ ТЕЧЕНИЯ ПОЛИНЕЙРОПАТИЙ, ОБУСЛОВЛЕННЫХ ГИПОТИРЕОЗОМ И АССОЦИИРОВАННЫХ С НАЛИЧИЕМ АНТИТЕЛ К ТИРЕОПЕРОКСИДАЗЕ И ТИРЕОГЛОБУЛИНУ
}

\begin{abstract}
Оржешковский В.В.*, Ткаченко Е.В.
Нацчиональная медицинская академия последипломного образования имени П.Л.Шупика, Киев, Украина

В статье представлено исследование 56 пациентов с полинейропатиями, ассоциированных с наличием антител к тиреопероксидазе, тиреоглобулину (32 пациента) и обусловленных гипотиреозом (24 пациента). Проведено сравнительное исследование клинических, электромиографических и лабораторных характеристик, на основании чего определены характерные особенности необходимые для постановки правильного диагноза и возможного разграничения данной патологии. Преобладающей клинической формой полинейропатии, ассоциированной с наличием антител к тиреопероксидазе и тиреоглобулину является мотосенсорная демиелинизирующая полинейропатия с характерной клинической картиной и электромиографическими маркерами демиелинизации. Высказано предположение о едином патогенетическом механизме поражения нервной системы при энцефалопатии Хашимото и полинейропатии, ассоциированной с наличием антител к тиреопероксидазе и тиреоглобулину. Отмечена необходимость наряду с лабораторным определением тиреотропного гормона и свободного тироксина, также и антител к тиреопероксидазе и тиреоглобулину.

Ключевые слова: антитела к тиреопероксидазе, антитела тиреоглобулину, гипотиреоз, дистальная симметричная полинейропатия, стимуляционная электромиография.
\end{abstract}

Поражение нервной системы и в частности ее периферического отдела достаточно часто сопровождает заболевания щитовидной железы (ЩЖ). Важным и актуальным является изучение связи патологии нервной системы с наличием антител к структурам ЩЖ, в частности к тиреопероксидазе (АТПО) и тиреоглобулину (АТТГ), которые регистрируются у пациентов с тиреоидитом Хашимото, при гипотиреозе (в 47-83\% случаев), при других аутоиммунных эндокринных заболеваниях (например, при сахарном диабете I типа - 15$30 \%$ случаев, целиакии - 8\%, болезни Аддисона - 23-40\%), а также могут встречаются в популяции в 2-10\% случаев, клинически интактных в отношении ЩЖ [1]. С наличием этих антител связывают достаточно серьезное поражение нервной системы - энцефалопатию Хашимото, при которой возможно повреждение центральной нервной системы, даже в отсутствии нарушения функции либо значимой патологии ЩЖ [9]. Патогенез этой патологии требует уточнения, предполагается аутоиммунно обусловленное повреждение сосудистого эндотелия и/или нейрональное повреждение [6]. По поводу же повреждений периферической нервной системы (ПНС), ассоциированных с АТПО и АТТГ в литературе имеются лишь единичные описания клинических случаев, в которых прослеживается неоднозe-mail: neurology-education@ukr.net начность генеза повреждения ПНС, учитывая, что снижение функции ЩЖ может оказывать повреждающее действие на ПНС $[2,4,7]$. Так, при гипотиреозе полинейропатия (ПНП) достаточно частая патология (42\% в этой группе пациентов) и представлена преимущественно в виде сенсомоторной аксональной полинейропатии, у части больных возможно развитие парезов, а также эта патология часто ассоциирована с синдромом карпального канала $[3,8]$. Целью нашего исследования было определение характерных клинико-нейрофизиологических показателей в группе пациентов с полинейропатией, ассоциированной с наличием антител к тиреопероксидазе, тиреоглобулину путем сравнения с клинико-электромиографическими характеристиками в группе с полинейропатией обусловленной гипотиреозом.

Материал и методы исследования. Под нашим наблюдением находилось 56 пациентов в возрасте от 20 до 59 лет, из которых 32 с полинейропатией ассоциированной с наличием антител к тиреопероксидазе (АТПО) и тиреоглобулину (АТТГ) (1 группа; средний возраст 44,5 22,1 лет; 1 мужчина и 32 женщины) без признаков снижения функции щитовидной железы и 24 с полинейропатией, обусловленной гипотиреозом без наличия антител к тиреопероксидазе и тиреоглобулину (2 группа; сред-

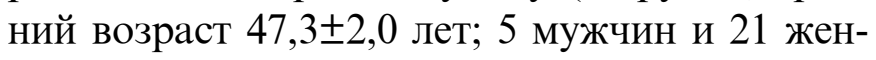


щина). В первой группе регистрировалось повышение уровня АТПО (варьировало от 59,5 до $352,5 \mathrm{ME/мл,} \mathrm{среднее} \mathrm{значение} 236,0 \pm 23,8$ МЕ/мл) и АТТГ (варьировало от 237,4 до 601,2

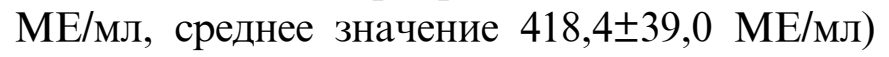
при отсутствии повышения уровня тиреотропного гормона (ТТГ). Во второй группе отмечалось повышение уровня ТТГ (варьировало от 4,29 до 8,21 мкМЕ/мл, среднее значение $6,06 \pm 0,3$ мкМЕ/мл) и снижение уровня свободного тироксина (FT4) (варьировало от 0,76 до 0,92 мкМЕ/мл, среднее значение 0,84 $\pm 0,02$ мкМЕ/мл), без наличия значимого повышения уровня АТПО и АТТГ. Все пациенты обеих групп имели признаки поражения ПНС, основу которой составила дистальная симметричная полинейропатия (ДСП). Всем пациентам было проведено клинико-неврологическое исследование с определением баллов по шкале TCNSS (Toronto Clinical Neuropathy Scoring System), нейропатического дисфункционального счета (НДС) и по опроснику PainDetect, a также стимуляционная электромиография (ЭМГ) на аппарате "Нейрон-Спектр-4/ВПМ" (Российская Федерация) с исследованием Мответа и скорости распространения возбуждения по моторным волокнам (СРВм) n.tibialis, n.peroneus, n.medialis, n.ulnaris, а также поздних ответов (F-волна) и скорости распространения возбуждения по сенсорным волокнам $(\mathrm{CPBc})$ n.saphenus, n.suralis, n.medialis, n.ulnaris, а также избирательно по показания проводилась игольчатая ЭМГ с регистрацией спонтанной активности и анализом потенциалов двигательных единиц. Полученный материал был обработан методами описательной и непараметрической статистики, корреляционного анализа с помощью пакета "Statistica 10".

Результаты исследования и обсуждение. В результате проведенного исследования получены следующие результаты. Средний балл составил по шкале TCNSS в первой группе $8,4 \pm 0,3$, а по шкале НДС 9,7 $\pm 0,4$, во второй группе $7,4 \pm 0,2$ и $8,5 \pm 0,3$ соответственно, что соответствует умеренно выраженной полинейропатии. Причем эти показатели имели статистически значимую разницу в сравнении двух групп по шкале TCNSS - p<0,02, а по шкале НДС - $\mathbf{p}<0,05$, что свидетельствовало о несколько более выраженной клинике поражения ПНС в первой группе. Во второй группе наряду с ПНП у 4 (16,7\%) пациентов отмечалась клиника типичной миопатии с поражением мышц тазового пояса, которая подтверждалась данными игольчатой ЭМГ, а также одна пациентка имела вовлечение в патологический процесс тройничного нерва справа по типу невралгонейропатии. В первой группе пациенты с миопатией и вовлечением черепных нервов отсутствовали, однако у 2 пациентов регистрировались гиперинтенсивные очаги в Т2 режиме на МРТ головного мозга. У 3 (12,5\%) пациентов 2 группы и у 5 (15,6\%) 1 группы отмечалась клиника синдрома карпального канала, которая была подтверждена с помощью ЭМГ. В 1 группе у $9(28,1 \%)$ пациентов регистрировалась клиника поражения локтевого нерва в кубитальном канале с чувствительными и двигательными расстройствами, а во 2 - подобных клинических проявлений зафиксировано не было $(p<0,02)$. Нейропатический болевой синдром (по опроснику PainDetect) встречался в единичных случаях как в 1, так и в 2 группе при синдроме карпального канала, боль имела характерную локализацию. В 1 группе клиника ПНП была представлена преимущественно мотосенсорным вариантом в 46,9\% (15 пациентов), с некоторой асимметрией двигательных и чувствительных расстройств, во 2 группе подобная клиника отмечалась лишь в 8,3\% (2 пациента) $(\mathrm{p}<0,02)$. Кроме того, у $4(12,5 \%)$ пациентов 1 группы более выраженные проявления ПНП были отмечены на верхних конечностях, а во 2 группе - только у 1 пациента.

По данным стимуляционной ЭМГ практически у всех пациентов обеих групп отмечалось поражение сенсорных волокон, которое верифицировалось снижением показателей CPBc: CPBc n.medialis 41,8 1,7 м/с (1 группа) и $40,9 \pm 1,5$ м/с (2 группа), СРBc n.ulnaris 40,4 $\pm 2,1$

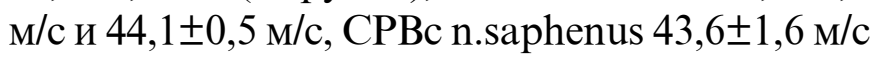
и $40,1 \pm 1,4 \mathrm{~m} / \mathrm{c}$, CPBc n.suralis $43,2 \pm 1,7 \mathrm{м} / \mathrm{c}$ и $44,7 \pm 0,9$ м/с соответственно, однако статистически достоверной разницы этих показателей между группами не выявлено ( $>>0,05)$. Элект- 
ромиографические признаки миелинопатии моторных волокон выявлялись в 1 группе у 21 пациента (65,6\%), а во 2 групе лишь у $6(25 \%)$, что имело статистически достоверную разницу $(\mathrm{p}<0,007)$. Следующие ЭМГ показатели имели статистически достоверную разницу между группами. Наличие блоков проведения по n.tibialis 1 группе регистрировалось у 13 пациентов (40,6\%), а во 2 группе у $4(16,7 \%)$ $(\mathrm{p}<0,04)$, кроме того в 1 группе отмечалась прямая корреляционная зависимость показателя с уровнем АТПО $(\mathrm{r}=0,59)$. Наличие блоков проведения по n.medialis представлены в 1 группе у 9 пациентов $(28,1 \%)$ в 2 группе не встречалось $(\mathrm{p}<0,05)$, по n.ulnaris в 1 группе у $24(75 \%)$, а во 2 у $4(16,7 \%)(p<0,0003)$. Снижение СРВм n.ulnaris в 1 группе отмечалось у 13 пациентов (40,6\%), а во 2 только у $2(8,3 \%)$ $(\mathrm{p}<0,02)$ и имелась в 1 группе прямая корреляционная зависимость показателя с уровнем АТТГ $(\mathrm{r}=0,52)$. Снижение амплитуды М-ответа n.peroneus встречалось в 1 группе у 28 пациентов $(87,5 \%)$, а во 2 группе у $10(41,7 \%)$ $(\mathrm{p}<0,02)$ и также отмечалась прямая корреляционная зависимость показателя с уровнем ATПО $(r=0,53)$ и АТТГ $(r=0,5)$. Увеличение peзидуальной латентности (РЛ) n.peroneus представлено в 1 группе у 11 пациентов $(34,4 \%)$ во 2 группе не встречалось $(\mathrm{p}<0,008)$ и также отмечалась прямая корреляционная зависимость показателя с уровнем АТТГ $(\mathrm{r}=0,59)$. Снижение амплитуды М-ответа n.medialis в 1 группе отмечалось у 9 пациентов $(28,1 \%)$ во 2 группе не встречалось $(\mathrm{p}<0,02)$. Учитывая описанную клинику полинейропатий, ассоциированных с наличием антител к тиреопероксидазе и тиреоглобулину пациенты со схожей клиникой и указанием на возможную патологию ЩЖ тре-

\section{ЛИТЕРАТУРА}

1. A. Van den Driessche, V. Eenkhoorn, L. Van Gaal, C. De Block. Type 1 diabetes and autoimmune polyglandular syndrome: a clinical review/ The Netherlands Journal of Medicine. December 2009,vol.67,№11:376-387.

2. Bairactaris C, Stouraitis G, Papalias E, et al. Early neurophysiological evolution of chronic inflammatory demyelinating polyneuropathy in a patient with Hashimoto's thyroiditis./ J Neurol Sci. 2005 Nov 15;238(12):105-7.

3. Bernhard Neundörfer, Dieter HeuB. Polyneuropathien. буют обязательного определения уровня этих антител при наличии данных о патологии щитовидной железы, а не только тиреотропного гормона и свободного тироксина [5].

В результате выше изложенного можно сделать следующие выводы.

1. Полинейропатии, ассоциированные с наличием антител к тиреопероксидазе и тиреоглобулину имеют отличия в клинической и нейрофизиологической картине от полинейропатий обусловленных только гипотиреозом. Это указывает на целесообразность комплексного лабораторного исследования показателей ЩЖ, включая гормоны и антитела, у пациентов с полинейропатией.

2. По видимому полинейропатии, ассоциированные с наличием антител к тиреопероксидазе и тиреоглобулину имеют схожий с энцефалопатией Хашимото генез поражения структур нервной системы, аутоиммунной направленности. Преобладающей клинической формой полинейропатии, ассоциированные с наличием антител к тиреопероксидазе и тиреоглобулину является мотосенсорная демиелинизирующая полинейропатия с характерной клинической картиной и электромиографическими маркерами демиелинизации - блоки и снижения скорости проведения по моторным волокнам периферических нервов, увеличение резидуальной латентности, которые коррелируют с уровнем указанных антител.

3. Полинейропатии, ассоциированные с наличием антител к тиреопероксидазе и тиреоглобулину протекают менее благоприятно полинейропатий, обусловленных гипотиреозом, без повышения уровня указанных антител с преимущественным вовлечением в патологический процесс сенсорных волокон, иногда в сочетании с миопатией с поражением мышц тазового пояса.

Georg Thieme Verlag, Stuttgart, 2007. 129s.

4. Elisabeth A. Cats, Anne Suzanne Bertens, Jan H. Veldink et al. Associated autoimmune diseases in patients with multifocal motorneuropathy and their family members./ J Neurol (2012) 259:1137-1141

5. Gary Gallagher et al. Value of thyroid and rheumatologic studies in the evaluation of peripheral neuropathy/ Neurology: Clinical Practice, April 2013: 90-98.

6. Juraj Payer, Tomas Petrovic, Lubomir Lisy, Pavel Langer. Hashimoto Encephalopathy: A Rare Intricate 
Syndrome/ Int J Endocrinol Metab. 2012;10(2): 506-514

7. Suk-Won Ahn,a Su-Hyun Kim,b Byung-Su Park et al. Concurrence of Multifocal Motor Neuropathy and Hashimoto's Thyroiditis/ J Clin Neurol 2011;7:168-172
8. Textbook of Peripheral Neuropathy/ editor Peter D. Donofrio. Demos Medical Publishing, New York, 2012. 475p. 9.Yoneda M. [Hashimoto's encephalopathy and autoantibodies]./ Brain Nerve. 2013 Apr;65(4):365-76.

XÜLASO

\title{
HIPPOTİREOZ SӘBӘBLİ VO TİREOPEROKSIDAZA VӘ TIREOQLOBULINO QARŞI ANTICISIMLORLӘ ӘLAQӘLI POLINEYROPATIYALARIN GEDISSINININ XÜSUSIYYYOTLORİ
}

\author{
Orjeshkovskiy V.V., Tkaçenko E.V. \\ P.L.Supik adina Diplomdan Sonrakı Milli Tibb Akademiyası, Kiyev, Ukrayna
}

Təqdim edilmiş məqalədə tireoperoksidazaya, tireoqlobulina (32 pasiyent) qarşı anticimlərlə əlaqəli və hipotireoz (24 pasiyent) səbəbli polineyropatiyası olan 56 pasiyentin cəlb edilməsi ilə tədqiqatın nəticələri göstərilmișdir. Klinik, elektromioqrafik və laborator müayinələrin nəticələrinin müqayisəli tədqiqatı aparılmış, bunun əsasında bu patologiyanın düzgün diaqnozunun qoyulması və qarșısını almaq üçün xarakter xüsusiyyətlər təyin edilmişdir. Tireoperoksidazaya və tireoqlobulinə qarşı anticisimlərin olması ilə assosiasiyaolunmuş polineyropatiyaların ən çox rast gəlinən klinik forması demielinizasiyanın xarakter klinik mənzərəsi və elektromioqrafik markerləri ilə motosensor demielinizasiyaedici polineyropatiyadır. Tireoperoksidazaya və tireoqlobulinə qarșı anticisimlərin olması ilə assosiasiyaolunmuş polineyropatiya və Xașimoto ensefalopatiyas1 zamanı sinir sisteminin zədələnməsinin vahid patogenetik mexanizmi barədə fikirlər irəli sürülmüșdür. Tireotrop hormonun və müstəqil tiroksinin laborator təyini ilə yanaşı tireoperoksidazaya və tireoqlobulinə qarŞ1 anticisimlərin də təyininin vacibliyi qeyd edilmişdir.

Açar sözlər: tireoperoksidazaya qarşı antitellər, tireoqlobulinə qarşı antitellər, hipotireoz, distal simmetrik polineyropatiya, stimulyasion elektromioqrafiya.

\section{SUMMARY \\ CLINICAL FEATURES POLYNEUROPATHY THE RESULTING HYPOTHYROIDISM AND ASSOCIATED WITH PRESENCE OF ANTIBODIES TO THYROID PEROXIDASE AND THYROGLOBULIN}

\author{
Orzheshkovskyi V.V., Tkachenko E.V. \\ Shupyk National Medical Academy of Postgraduate Education, Kiev, Ukraine
}

The article presented a study 56 patients with polyneuropathy associated with the presence of antibodies to thyroid peroxidase, thyroglobulin (32 patients) and the resulting hypothyroidism (24 patients). A comparative study of clinical, laboratory and electromyographic characteristics of which are defined on the basis of characteristics needed for a correct diagnosis and eventual differentiation of this disease. The predominant clinical form of polyneuropathy associated with the presence of antibodies to thyroid peroxidase and thyroglobulin is motor and sensory demyelinating polyneuropathy with characteristic clinical and electromyographic markers demyelination. It is suggested that a common pathogenetic mechanism of the nervous system with Hashimoto's encephalopathy and polyneuropathy associated with the presence of antibodies to thyroid peroxidase and thyroglobulin. Noted the need with laboratory determination of thyroid-stimulating hormone and free thyroxine, and antibodies to thyroid peroxidase and thyroglobulin antibodies.

Keywords: antibodies to thyroid peroxidase, thyroglobulin antibodies, hypothyroidism, distal symmetric polyneuropathy, stimulating electromyography.

Redaksiyaya daxil olub: 09.11.2015

Çapa tövsiyo olunub: 30.11 .201

Rayçi: prof. Şiraliyeva R.K. 